\title{
Contribution of Nanotechnology in the Fight Against COVID-19
}

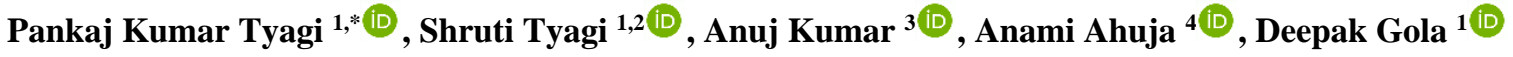 \\ 1 Department of Biotechnology Noida Institute of Engineering and Technology Greater Noida U.P. India \\ 2 Young Scientist, CST-UP Project, Noida Institute of Engineering and Technology Greater Noida U.P. India \\ 3 Council of Biotechnology (UCB) Pantnagar, India \\ 4 Research Scholar APJ Abdul Kalam Technical University Lucknow U.P. India \\ * Correspondence: pktgenetics@gmail.com;
}

Scopus Author ID 34881106500

Received: 1.07.2020; Revised: 18.07.2020; Accepted: 19.07.2020; Published: 22.07.2020

\begin{abstract}
Coronavirus disease (COVID-19) is a respiratory infectious disease caused by a newly discovered virus strain, severe acute respiratory syndrome coronavirus-2 (SARS-Cov-2). This pandemic spread quickly across nations with a high mortality rate in immunocompromised patients. This contagious disease posed a serious threat to health systems. It impacted the continents of the earth in a way that could not have been predicted. Therefore, many leading funding agencies announced the call for proposal to diagnosis and treatment of COVID-19 pandemic using advanced technology-based methods, including nanotechnology. The researchers coming from the nanotechnology community can contribute their efforts to cope with COVID-19. As a community member of nanotechnology, we suggest some new research targets that can be designed and improved, optimized, and developed the existing/new materials in the sub-field of diagnostics and healthcare of nanotechnology. The potential research targets to fight against COVID-19 includes Point-of-care diagnostics (POCD), surveillance and monitoring, novel therapeutics, vaccine development, research, and development, repurposing existing drugs with potential therapeutic applications, development of antiviral nanocoating/antimicrobial spray-based coating for PPE, magnetic nanoparticles and viral RNA and rapid detection kits.
\end{abstract}

Keywords: coronavirus disease; nanotechnology community; point-of-care diagnostics; rapid detection kits; viral RNA.

(C) 2020 by the authors. This article is an open-access article distributed under the terms and conditions of the Creative Commons Attribution (CC BY) license (https://creativecommons.org/licenses/by/4.0/).

\section{Introduction}

The outbreak of coronavirus infectious disease (COVID-19) was the first time that emerged in December 2019 in Wuhan, a city in China's Hubei province with a population of about 11 million. This contagious disease has quickly spread over the 213 countries and territories around the world with a high mortality rate in critically ill This respiratory infectious disease has been declared as a sixth Public Health Emergency of International Concern (PHEIC) by World Health Organization (WHO) on 30 ${ }^{\text {th }}$ January 2020 (Mackenzie \& Smith, 2002; www.who.int). The statistics of COVID-19 pandemic has led to over 10251173 confirmed cases, and 504520 fatalities as on $29^{\text {th }}$ June 2020 (https://covid19.who.int/) The new cases across the nations are increasing abruptly. To date, there is no drug that has proved to be effective for the treatment of COVID-19 that have a high frequency of genomic recombination and mutation [1-3]. Coronaviruses have been characterized as highly diverse, enveloped, 
positive-sense, and single strand-RNA viruses [3-5]. So far, six known species of human coronavirus have been discovered, including HCoV-NL63, HCoV-229E, HCoV-OC34, HCoV-HKU1, SARS-CoV and MERS-CoV, all of them found directly associated with respiratory tract diseases [6-10]. The newly discovered SARS-Cov-2 has been characterized as a seventh strain of human coronavirus [11]. Based on the whole genome sequencing and functional annotations, the Coronavirus Study Group (CSG) taxonomically placed the SARSCov-2 with Genre Betacoronavirus [12,13]. In the last two decades, two other CoVs, namely, severe acute respiratory syndrome $\mathrm{CoV}$ (SARS-CoV) and Middle East respiratory syndrome $\mathrm{CoV}$ (MERS-CoV), have been reported and cause severe human diseases. Whole-genome alignment (WGA) revealed that COVID-19 shared the $89.1 \%$ and $60 \%$ sequence identity with SARS and MERS CoVs, respectively [5,11]. The viral membrane is studded with spikes of glycoprotein that give coronaviruses a similar appearance to their crown. Although coronaviruses infect both humans and animals, some animal types, such as bats that host the widest range of coronaviruses, tend to be immune to coronavirus-induced disease [14]. The most common symptoms of COVID-19 are cough, fever, shortness of breath, and trouble breathing. In more serious cases, pneumonia, extreme acute respiratory syndrome, and even death may result from infection. The symptoms will show within 2-14 days. If the virus spread is not effectively managed in the immediate future, the wavelet impact of this epidemic could theoretically pose significant challenges to the global health division and as well as far-reaching implications for the world economy [15-17].

In a recent study, a panel of recognized pathogens was used to screen the infected person with pneumonia-like symptoms and their irregular lung computed tomography (CT) images using a polymerase chain reaction multiplex (PCR) (Ref). It has produced negative results. On $10^{\text {th }}$ January 2020 , the previously unknown pathogen was identified as an RNA virus through next-generation sequencing (NGS) approach. Its genome sequencing showed that the novel virus in 2002-2003 was identical to SARS-CoV, the virus that caused SARS, and it was called SARS-CoV-2. Four types of coronaviruses are called alpha, beta, gamma, and delta. Extreme acute respiratory syndrome (SARS) virus (SARS-CoV), Middle East respiratory syndrome (MERS) virus (MERS-CoV), and Covid-19 causative agent SARS-CoV-2 are included in the beta coronavirus class. SARS-CoV-2 affects the lower respiratory system to induce viral pneumonia and can also damage the immune system, heart, kidney, liver, and central nervous system leading to multiple organ failure $[9,18]$. Current information available in public repositories suggests that SARS-CoV-2 is more transmissible/contagious than SARSCoV [19]. Based on the availability of whole-genome sequence data of COVID-19, suffering patients diagnosed recently using developed PCR kits. Besides, the scientist and researcher of CDC have also developed rRT-PCR panel for detection, isothermal amplification tests, serological tests, and lateral flow assays to diagnose COVID-19 [20]. Chest CT scans can be effective in diagnosing Covid-19 in people with a strong clinical suspicion of infection based on risk factors and symptoms but are not recommended for regular screening. However, the diagnostic test developments and their regulatory approvals, researchers are now testing different drug formulations to treat Covid-19 patients. Some of the therapies are conducted through clinical trials in which the most common is the trial of Lopinavir and Ritonavir in adults hospitalized with severe COVID-19. The result of this is that in hospitalized adult patients with extreme Covid-19 therapy, no gain was observed beyond standard care with Lopinavir-Ritonavir. Future studies in critically ill patients can help to confirm or exclude the possibility of a treatment gain. Other recent multicentre clinical trial and cell culture studies 
indicate that chloroquine, the 70-year-old malaria drug, may potentially demonstrate therapeutic efficacy against COVID-19 (Coronavirus disease 2019). In favor of disease prevention, several vaccine candidates are being tested globally against SARS-CoV-2, and some have recently entered the last phases of clinical trials [21]. The scientific community hopes that an effective vaccine is expected for at least 8-12 months.

\section{Research gaps and future prospectives for nanotechnologist}

Keeping in mind this pandemic COVID-19 infection and bullet spreading, all the nations across the globe should concentrate $\mathrm{s}$ to make stronger their healthcare system than before. The researchers of the nanotechnology community can contribute their efforts against the fight COVID-19. As a team member of the nanotechnology community, we are suggesting the following research targets (Figure 1).

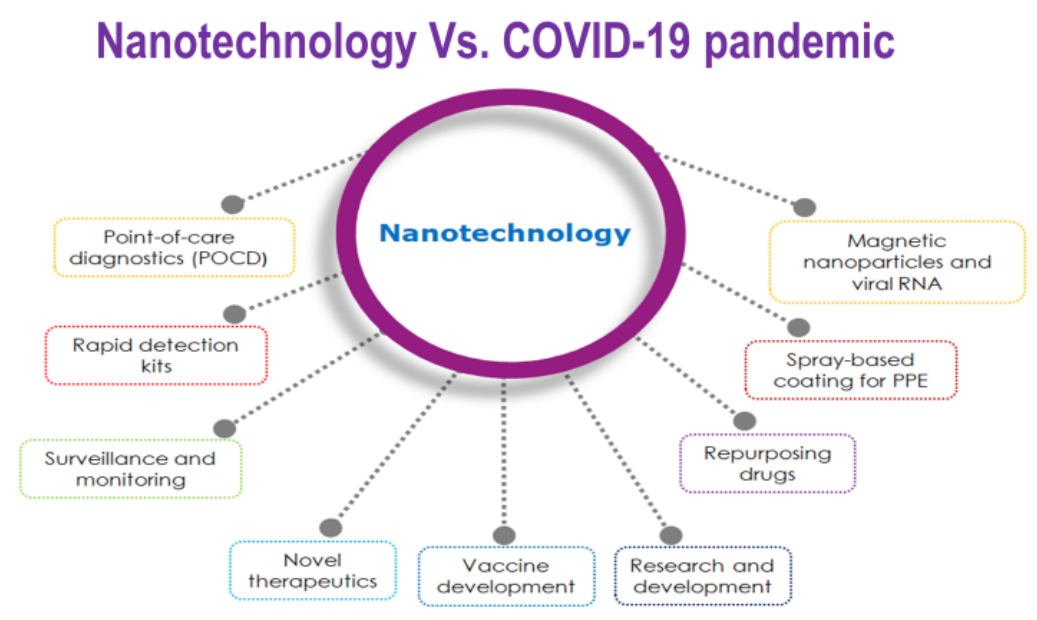

Figure 1. Potential research targets of nanotechnology to fight against COVID-19.

\subsection{Point-of-care diagnostics (POCD).}

Point-of-care diagnostics (POCD) or with-patient testing helps doctors and medical personnel to reliably produce diagnostic outcomes in real-time, laboratory quality within minutes and not hours. Coronavirus-positive individuals with a wide variety of symptoms such as other respiratory illnesses (e.g., fever, cough, and shortness of breath) or maybe silent carriers. Such related symptoms generate uncertainty and substantial concern about the spread of Covid-19 at the community level. The availability in emergency rooms, clinics, and community hospitals of a cost-effective, fast point-of-care diagnostic test is critical. These diagnoses allow frontline workers to triage patients and avoid further coronavirus spread quickly, and we need to change our diagnosis methods. The nanotechnologist can help in this area for making some advances in POCD, which are a result of continuous developments in nanosensor technology, microfluidic channel devices, bioanalytical platforms, assay formats, lab-on-a-chip technologies, and complementary technologies. In the past 2-3 years, several prospective POCD has been developed, which are paving the way to next-generation POCT [22].

\subsection{Surveillance and monitoring.}

Surveillance with rapid diagnostic tools helps public health officials to track the spread of viruses, proactively identify areas with infections, predict the need for surge capacity, and 
allocate the required resources to the relevant areas. Simple and open coordination and cooperation between central governments, major public health labs, hospitals, government departments, and communities depend on the results of such a program. The WHO and others have argued that widespread testing will be needed to stop this pandemic [21]. Individuals in the community can play an important role in the surveillance of COVID-19. Where possible, individuals who have signs and symptoms of COVID-19 should be able to access testing at the primary care level. Where testing at the primary level is not possible, community-based surveillance, whereby the community participates monitors and reports health events to local authorities, may be helpful for identifying clusters of COVID-19 (Surveillance strategies for COVID-19 human infection). Nanotechnologists and software engineers should be designed computer-based applications in which the individuals fill their health signs and symptoms and get the health status report as output. In India government launch aarogya setu apps, and it is working in the right direction but may need to optimized and improved.

\subsection{Therapeutics.}

Proper care and monitoring of COVID-19 patient is required for recovery. Although various drugs and vaccines have shown effectiveness, however no therapy in the form of vaccine or drug has been approved for COVID-19 to date. Detailed research is required to understand the mechanisms involved during the interaction of SARS-CoV-2 with the host cell (e.g., binding of SARS-CoV-2 with angiotensin-converting enzyme receptor 2, ACE2), these findings may help in the development of new therapeutic agents to inhibit the interaction. In a study, it was observed that selenium based nanoparticles coated with the oseltamivir drug, is capable of inhibiting the interaction of H1N1 coat protein with the host cell [23]. Similarly, a potent drug can be loaded on the nanoparticles that can interfere with the interaction of SARSCoV-2 and ACE2, inhibiting the viral infection inside the host.

\subsection{Vaccine development.}

Vaccines are the most effective medication that completely or to some extent, lower down the chances of pathogenic infection by strengthening the immune system. Nanoparticlebased vaccines can play an important role in this direction. For example, a maltodextrin nanoparticle-formulated vaccine was found effective against influenza virus infection [24]. As per the reports, a total of 115 vaccines are under developmental stages against COVID19 [25]. As per the available data, the nanoparticle-based mRNA-1273 vaccine developed by the Moderna (American Biotech Company) is under phase 1 trial. The main characteristic of the mRNA-1273 vaccine is its lipid nanoparticle-encapsulated mRNA vaccine that code for the $S$ protein.

Moreover, the SARS-CoV-2 virus shows substantial sequence homology with two other deadly viruses, i.e., SARS and MERS. The nanoparticles based vaccine studies against the SARS and MERS may play an important role in facilitating the design of anti-SARS-Co-2 vaccines [26-28]. Hence, developing a safe and efficient nano-based vaccine can manage the spread of Covid-19. 


\subsection{Research and development.}

Identifying targets is necessary to discover the potential drugs with high target specificity or to discover existing drugs that could be repurposed to treat the infection with SARS-CoV-2. Already existing potential targets, their functions in viral infection, and current representative drugs or drug candidates that are known to be acting on the corresponding targets in related viruses and are therefore to be tested for their effects on SARS-CoV-2. 3CLpro and PLpro are two viral proteases responsible for the cleavage of viral peptides into virus replication and packaging functional units within the host cell. Thus, drugs that target these proteases can be studied in other viruses. RdRp is the RNA polymerase responsible for the synthesis of viral RNA that may be inhibited by current antiviral drugs or may also be evaluated by drug candidates.

\subsection{Existing drugs with potential therapeutic applications.}

SARS-CoV-2 is a newly discovered pathogen; until now, no specific drug is available at present. The repurpose of patented drugs is an economical and successful therapeutic technique. So far, different drugs have been repurposed for the treatment of the COVID-19, which includes antimalarial drugs (Chloroquine and its derivative Hydroxychloroquine), antiviral drugs (HIV Protease Inhibitors, i.e., Lopinavir and Ritonavir), investigational nucleoside analog [Remdesivir (GS-5734)], and investigational RNA-dependent RNA polymerase inhibitor (Favipiravir) [29-34]. Several adjunctive therapeutic drugs have also been utilized for the treatment of COVID-19, such as macrolide antibacterial drug (Azithromycin), Interleukin-6 (IL-6) Receptor-Inhibiting Monoclonal Antibody (Tocilizumab, Sarilumab) and Investigational Humanized Monoclonal Antibody to the Chemokine Receptor CCR5 (Leronlimab) [35-39]. However, among the repurposed drugs Chloroquine and Hydroxychloroquine were highly recommended for the treatment of the COVID-19 in different countries, including China, the USA, and India [31,40,41]. Based on the detailed biological surveys, many recent studies questioned the safety and reported the severe adverse effects of Chloroquine and Hydroxychloroquine [31,42]. The nanotechnology and biotechnology methods-based efforts are going to react rapidly to established drugs with therapeutic potential against COVID-19 with the fruitful utilization of available genomic sequence knowledge coupled with protein 3D structure modeling [43,44].

\subsection{Development of personal protective equipment (PPE).}

The magnetic nanomaterials coating will be used on masks, eye-protecting glasses, and other protective gear used by healthcare workers for developing antiviral nanocoated Personal Protective Equipment (PPE). PPE which are usually used to protect the wearer from infectious microbes / aqueous virus droplets acting as a shield. This PPE, however, typically do not have the ability to prevent the spread of microbes as the fabric surface readily allows microbes to bind and grow over time. This leads to more microbial spread due to poor handling of PPE and inappropriate disposal procedures. Nanotechnology group can attempt to develop certain products that protect healthcare workers and people from current coronavirus and other infectious diseases. 


\subsection{Magnetic nanoparticles and viral RNA.}

Iron oxides nanoparticles are very well known for their antimicrobial properties against pathogenic bacteria and fungi [45,46]. Studies indicated that iron oxide nanoparticles could play a major role in the COVID-19 outbreak. According to the news published by Nanowerk (08, April 2020) [47], Norway is using kits that contain immobilized iron nanoparticles on silica to identify COVID-19 positive cases. These nanoparticles show a strong affinity for the RNA (genetic material) present in the coronavirus. Collaborative works by Norwegian University of Science and Technology (NTNU) and St. Olavs Hospital lead to the development of the COVID-19 testing method exploiting the magnetic properties of iron oxide nanoparticles to attract the RNA present in the sample collected from the suspected or infected COVID-19 patients. The testing methods also contain a substance that helps in the extraction of RNA from the virus. Further, the extracted RNA is strongly attracted to the silica-covered magnetic nanoparticles. The next step is to use a magnet to pull the RNA-covered particles out of the solution and identifying the genetic code of RNA. In the last step, the available genetic code of RNA is compared to the genetic code of coronavirus to conclude the result of the sample. The developer of the kit also states that the iron oxide nanoparticles method is more sensitive than commercially available tests. The above technology can revolutionize the testing method of COVID-19 patients because of its cost-effectiveness, easy production, accuracy, and sensitivity.

\subsection{Rapid detection kits.}

Currently, the researcher at the World Nano Foundation successfully developed a rapid nano-gold test to screen out the COVID-19 positive cases. This nano-gold kit based on $\mathrm{IgM} / \mathrm{IgG}$ antibody assay and takes less than 15 minutes to produce the results [48]. It is user's friendly and does not require costly instruments like PCR (polymerase chain reactor). This nanotechnology-based testing kit has a great potential benefit for the quick screening of COVID-19 infections. Further, the CE mark certification has already been issued to the kit. More such efforts are required by the nanotechnology research community to develop other effective kits, which not only be cheap but can also provide accurate results in a few minutes. These gaps/targets are important for nanotechnology community researchers/scientists to visualize, understand, and, perform research in this direction.

\section{Conclusions}

The Covid-19 infection and its rapid spreading in the whole world concentrate on making stronger their healthcare system. Many research grants may be opens for diagnosis and treated this pandemic Covid-19 globally. Many scientists, researchers, and technical persons are capable of doing research against this pandemic Covid-19. The molecular biologists, biochemists, chemists, data scientists, AI scientists and so many allied field researchers/ scientists are very important at this time. However, being at a nano-range, nanotechnology can develop or enhance the effect of any already developed technology. Therefore the role of nanotechnologists is very crucial, right from prevention, diagnosis, and treatment of COVID19. Various nano-scale drug delivery systems employing nano-capsule, biomagnetic nanoparticle, quantum dots, nanotubes, polymeric nanoparticles, provide a slow-release and targeted delivery of the required drug. Metallic nanoparticles, especially AgNPs, has already shown efficient antiviral activities. Therefore the surface coating of these nanoparticles in 
different materials like masks, medical devices, gloves, and other protective materials could be useful in the prevention of viral spread. Further, it has been reported that nanoparticle can efficiently interact with biomolecules, i.e., DNA and proteins, therefore employing nanoparticle in diagnosis, provides quick, sensitive, and accurate results.

\section{Funding}

This research received no external funding.

\section{Acknowledgments}

Authors gratefully acknowledge CST, Uttar Pradesh [Grant no: CST/8276 (young scientist scheme). The authors are highly thankful to the Chairman and Director of this Institute for their regular suggestions and cooperation.

\section{Conflicts of Interest}

The authors declare no conflict of interest.

\section{References}

1. Kumar, A.; Choudhir, G.; Shukla, S.K.; Sharma, M.; Tyagi, P.; Bhushan, A.; Rathore, M. Identification of Phytochemical Inhibitors against Main Protease of COVID-19 Using Molecular Modeling Approaches. $J$ Biomol Struct Dyn 2020, 1-11, https://doi.org/10.1080/07391102.2020.1772112.

2. $\quad$ Lai, C.C.; Shih, T.P.; Ko, W.C.; Tang, H.J.; Hsueh, P.R. Severe Acute Respiratory Syndrome Coronavirus 2 (SARS-CoV-2) and Coronavirus Disease-2019 (COVID-19): The Epidemic and the Challenges. International Journal of Antimicrobial Agents Elsevier $\quad$ B.V. 2020,55 , https://doi.org/10.1016/j.ijantimicag.2020.105924.

3. Fehr, A.R.; Perlman, S. Coronaviruses: An Overview of Their Replication and Pathogenesis. In: Coronaviruses: Methods and Protocols. Springer New York, 2015; pp. 1-23, https://doi.org/10.1007/9781-4939-2438-7_1.

4. He, X.; Lau, E.H.Y.; Wu, P.; Deng, X.; Wang, J.; Hao, X.; Lau, Y.C.; Wong, J.Y.; Guan, Y.; Tan, X.; Mo, X.; Chen, Y.; Liao, B.; Chen, W.; Hu, F.; Zhang, Q.; Zhong, M.; Wu, Y.; Zhao, L.; Zhang, F.; Cowling, B. J.; Li, F.; Leung, G.M. Temporal Dynamics in Viral Shedding and Transmissibility of COVID-19. Nat Med 2020, 26, 672-675, https://doi.org/10.1038/s41591-020-0869-5.

5. Chin, A.W.H.; Chu, J.T.S.; Perera, M.R.A.; Hui, K.P.Y.; Yen, H.L.; Chan, M.C.W.; Peiris, M.; Poon, L.L.M. Stability of SARS-CoV-2 in Different Environmental Conditions. The Lancet Microbe 2020, 1, https://doi.org/10.1016/s2666-5247(20)30003-3.

6. Arden, K.E.; Nissen, M.D.; Sloots, T.P.; Mackay, I.M. New Human Coronavirus, HCoV-NL63, Associated With Severe Lower Respiratory Tract Disease in Australia. J Med Virol 2005, 75, 455-462, https://doi.org/10.1002/jmv.20288.

7. Woo, P.C.Y.; Lau, S.K.P.; Chu, C.; Chan, K.; Tsoi, H.; Huang, Y.; Wong, B.H.L.; Poon, R.W.S.; Cai, J.J.; Luk, W.; Poon, L.L.M.; Wong, S.S.Y.; Guan, Y.; Peiris, J.S.M.; Yuen, K. Characterization and Complete Genome Sequence of a Novel Coronavirus, Coronavirus HKU1, from Patients with Pneumonia. J Virol 2005, 79, 884-895, https://doi.org/10.1128/jvi.79.2.884-895.2005.

8. De Wit, E.; Van Doremalen, N.; Falzarano, D.; Munster, V.J. SARS and MERS: Recent Insights into Emerging Coronaviruses. Nature Reviews Microbiology 2016, 14, 523-534, https://doi.org/10.1038/nrmicro.2016.81.

9. Su, S.; Wong, G.; Shi, W.; Liu, J.; Lai, A.C.K.; Zhou, J.; Liu, W.; Bi, Y.; Gao, G.F. Epidemiology, Genetic Recombination, and Pathogenesis of Coronaviruses. Trends in Microbiology. 2016, 490-502, https://doi.org/10.1016/j.tim.2016.03.003.

10. Khan, M.; Shaik, M.R.; Khan, S.T.; Adil, S.F.; Kuniyil, M.; Khan, M.; Al-Warthan, A.A.; Siddiqui, M.R.H.; Nawaz Tahir, M. Enhanced Antimicrobial Activity of Biofunctionalized Zirconia Nanoparticles. ACS Omega 2020, 4, 1987-1996, https://doi.org/10.1021/acsomega.9b03840.

11. Wu, C.; Chen, X.; Cai, Y.; Xia, J.; Zhou, X.; Xu, S.; Huang, H.; Zhang, L.; Zhou, X.; Du, C.; Zhang, Y.; Song, J.; Wang, S.; Chao, Y.; Yang, Z.; Xu, J.; Zhou, X.; Chen, D.; Xiong, W.; Xu, L.; Zhou, F.; Jiang, J.; Bai, C.; Zheng, J.; Song, Y. Risk Factors Associated With Acute Respiratory Distress Syndrome and Death in Patients With Coronavirus Disease 2019 Pneumonia in Wuhan, China. JAMA Intern Med 2020, https://doi.org/10.1001/jamainternmed.2020.0994. 
12. International Committee on Taxonomy of Viruses (ICTV) https://talk.ictvonline.org/ (accessed Jun 5, 2020).

13. Siddiqi, H.K.; Mehra, M.R. COVID-19 Illness in Native and Immunosuppressed States: A ClinicalTherapeutic Staging Proposal. Journal of Heart and Lung Transplantation 2020, 405-407, https://doi.org/10.1016/j.healun.2020.03.012.

14. Anthony, S.J.; Johnson, C.K.; Greig, D.J.; Kramer, S.; Che, X.; Wells, H.; Hicks, A.L.; Joly, D.O.; Wolfe, N.D.; Daszak, P.; Karesh, W.; Lipkin, W.I.; Morse, S.S.; Mazet, J.A.K.; Goldstein, T. Global patterns in coronavirus diversity. Virus evolution 2017, 3, https://doi.org/10.1093/ve/vex012.

15. Gorbalenya, A.E.; Baker, S.C.; Baric, R.S.; de Groot, R.J.; Drosten, C.; Gulyaeva, A.A.; Haagmans, B.L.; Lauber, C.; Leontovich, A.M.; Neuman, B.W.; Penzar, D.; Perlman, S.; Poon, L.L.M.; Samborskiy, D.V.; Sidorov, I.A.; Sola, I.; Ziebuhr, J. The Species Severe Acute Respiratory Syndrome-Related Coronavirus: Classifying 2019-NCoV and Naming It SARS-CoV-2. Nat Microbiol 2020, 5, 536-544, https://doi.org/10.1038/s41564-020-0695-Z.

16. Kupferschmidt, K.; Cohen, J. Will Novel Virus Go Pandemic or Be Contained? Science (80- ) 2020, 367, 610-611, https://doi.org/10.1126/science.367.6478.610.

17. Coronavirus Is Now Expected To Curb Global Economic Growth By $0.3 \%$ In 2020 https://www.forbes.com/sites/sergeiklebnikov/2020/02/11/coronavirus-is-now-expected-to-curb-globaleconomic-growth-by-03-in-2020/\#10b1351e16da (accessed Jun 5, 2020).

18. Zhu, N.; Zhang, D.; Wang, W.; Li, X.; Yang, B.; Song, J.; Zhao, X.; Huang, B.; Shi, W.; Lu, R.; Niu, P.; Zhan, F.; Ma, X.; Wang, D.; Xu, W.; Wu, G.; Gao, G. F.; Tan, W. A Novel Coronavirus from Patients with Pneumonia in China, 2019. N Engl J Med 2020, 382, 727-733, https://doi.org/10.1056/NEJMoa2001017.

19. Tang, B.; Bragazzi, N.L.; Li, Q.; Tang, S.; Xiao, Y.; Wu, J. An Updated Estimation of the Risk of Transmission of the Novel Coronavirus (2019-NCov). Infect Dis Model 2020, 5, 248-255, https://doi.org/10.1016/j.idm.2020.02.001.

20. Martínez-Castañón, G.A.; Niño-Martínez, N.; Martínez-Gutierrez, F.; Martínez-Mendoza, J.R.; Ruiz, F. Synthesis and Antibacterial Activity of Silver Nanoparticles with Different Sizes. J Nanoparticle Res 2008, 10, 1343-1348, https://doi.org/10.1007/s11051-008-9428-6.

21. Chan, W.C.W. Nano Research for COVID-19. ACS Nano. 2020, 14, 3719-3720, https://doi.org/10.1021/acsnano.0c02540.

22. Coronavirus map: Confirmed cases in the U.S.-Orange County Register https://www.ocregister.com/2020/03/05/coronavirus-map-confirmed-cases-in-the-u-s/ (accessed Jun 12, 2020).

23. Li, Y.; Lin, Z.; Guo, M.; Xia, Y.; Zhao, M.; Wang, C.; Xu, T.; Chen, T.; Zhu, B. Inhibitory Activity of Selenium Nanoparticles Functionalized with Oseltamivir on H1N1 Influenza Virus. Int J Nanomedicine 2017, 12, 5733-5743, https://doi.org/10.2147/IJN.S140939.

24. Quan Le, M.; Ye, L.; Bernasconi, V.; Carpentier, R.; Fasquelle, F.; Lycke, N.; Staeheli, P.; Betbeder, D. Prevention of Influenza Virus Infection and Transmission by Intranasal Administration of a Porous Maltodextrin Nanoparticle-Formulated Vaccine. Int J Pharm 2020, 582, https://doi.org/10.1016/j.ijpharm.2020.119348.

25. Coronavirus Vaccine Market Review 2020 - 2029(New Trending PDF )|Players - Inovio Pharmaceuticals, Novavax, Moderna - PharmiWeb.com https://www.pharmiweb.com/press-release/2020-03-03/coronavirusvaccine-market-review-2020-2029-new-trending-pdf-players-inovio-pharmaceuticals (accessed Jun 12, 2020).

26. Pimentel, T.A.P.F.; Yan, Z.; Jeffers, S.A.; Holmes, K.V.; Hodges, R.S.; Burkhard, P. Peptide Nanoparticles as Novel Immunogens: Design and Analysis of a Prototypic Severe Acute Respiratory Syndrome Vaccine. Chem Biol Drug Des 2009, 73, 53-61, https://doi.org/10.1111/j.1747-0285.2008.00746.x.

27. Coleman, C.M.; Liu, Y.V.; Mu, H.; Taylor, J.K.; Massare, M.; Flyer, D.C.; Glenn, G.M.; Smith, G.E.; Frieman, M.B. Purified Coronavirus Spike Protein Nanoparticles Induce Coronavirus Neutralizing Antibodies in Mice. Vaccine 2014, 32, 3169-3174, https://doi.org/10.1016/j.vaccine.2014.04.016.

28. Chen, W.H.; Strych, U.; Hotez, P.J.; Bottazzi, M.E. The SARS-CoV-2 Vaccine Pipeline: An Overview. Current Tropical Medicine Reports 2020, 7, 61-64, https://doi.org/10.1007/s40475-020-00201-6.

29. Beura, S.; Prabhakar, C. In-Silico Strategies for Probing Chloroquine Based Inhibitors against SARS-CoV2. J Biomol Struct Dyn 2020, 1-25, https://doi.org/10.1080/07391102.2020.1772111.

30. Gao, J.; Tian, Z.; Yang, X. Breakthrough: Chloroquine Phosphate Has Shown Apparent Efficacy in Treatment of COVID-19 Associated Pneumonia in Clinical Studies. BioScience Trends 2020, 14, 72-73, https://doi.org/10.5582/BST.2020.01047.

31. Wang, M.; Cao, R.; Zhang, L.; Yang, X.; Liu, J.; Xu, M.; Shi, Z.; Hu, Z.; Zhong, W.; Xiao, G. Remdesivir and Chloroquine Effectively Inhibit the Recently Emerged Novel Coronavirus (2019-NCoV) in Vitro. Cell Research 2020, 30, 269-271, https://doi.org/10.1038/s41422-020-0282-0.

32. Yao, T.T.; Qian, J.D.; Zhu, W.Y.; Wang, Y.; Wang, G.Q. A Systematic Review of Lopinavir Therapy for SARS Coronavirus and MERS Coronavirus-A Possible Reference for Coronavirus Disease-19 Treatment Option. Journal of Medical Virology 2020, 92, 556-563, https://doi.org/10.1002/jmv.25729.

33. Colson, P.; Rolain, J.M.; Lagier, J.C.; Brouqui, P.; Raoult, D. Chloroquine and Hydroxychloroquine as Available Weapons to Fight COVID-19. International Journal of Antimicrobial Agents 2020, 55, 
https://doi.org/10.1016/j.ijantimicag.2020.105932.

34. Chu, C.M.; Cheng, V.C.C.; Hung, I.F.N.; Wong, M.M.L.; Chan, K.H.; Chan, K.S.; Kao, R.Y.T.; Poon, L.L.M.; Wong, C.L.P.; Guan, Y.; Peiris, J.S.M.; Yuen, K.Y. Role of Lopinavir/Ritonavir in the Treatment of SARS: Initial Virological and Clinical Findings. Thorax 2004, 59, 252-256, https://doi.org/10.1136/thorax.2003.012658.

35. Gautret, P.; Lagier, J.C.; Parola, P.; Hoang, V.T.; Meddeb, L.; Mailhe, M.; Doudier, B.; Courjon, J.; Giordanengo, V.; Vieira, V.E.; Dupont, H.T.; Honoré, S.; Colson, P.; Chabrière, E.; La Scola, B.; Rolain, J.M.; Brouqui, P.; Raoult, D. Hydroxychloroquine and Azithromycin as a Treatment of COVID-19: Results of an Open-Label Non-Randomized Clinical Trial. Int $J$ Antimicrob Agents 2020, https://doi.org/10.1016/j.ijantimicag.2020.105949.

36. Chemotherapy, G.A.J. of A. Anti-Inflammatory Effects of Macrolides — an Underappreciated Benefit in the Treatment of Community-Acquired Respiratory Tract Infections and Chronic Inflammatory. 2005, https://academic.oup.com.

37. Beigelman, A.; Mikols, C.L.; Gunsten, S.P.; Cannon, C.L.; Brody, S.L.; Walter, M.J. Azithromycin Attenuates Airway Inflammation in a Mouse Model of Viral Bronchiolitis. Respir Res 2010, 11, https://doi.org/10.1186/1465-9921-11-90.

38. Zhou, F.; Yu, T.; Du, R.; Fan, G.; Liu, Y.; Liu, Z.; Xiang, J.; Wang, Y.; Song, B.; Gu, X.; Guan, L.; Wei, Y.; Li, H.; Wu, X.; Xu, J.; Tu, S.; Zhang, Y.; Chen, H.; Cao, B. Clinical Course and Risk Factors for Mortality of Adult Inpatients with COVID-19 in Wuhan, China: A Retrospective Cohort Study. Lancet 2020, 395 , 1054-1062, https://doi.org/10.1016/S0140-6736(20)30566-3.

39. Xu, X.; Han, M.; Li, T.; Sun, W.; Wang, D.; Fu, B.; Zhou, Y.; Zheng, X.; Yang, Y.; Li, X.; Zhang, X.; Pan, A.; Wei, H. Effective Treatment of Severe COVID-19 Patients with Tocilizumab. Proc Natl Acad Sci 2020, 117, https://doi.org/10.1073/pnas.2005615117.

40. Devaux, C.A.; Rolain, J.-M.; Colson, P.; Raoult, D. New insights on the antiviral effects of chloroquine against coronavirus: what to expect for COVID-19? International Journal of Antimicrobial Agents 2020, 55, https://doi.org/10.1016/j.ijantimicag.2020.105938.

41. Gonzalez-Paz, L.; Lossada, C.; Moncayo, L.; Romero, F.; Paz, J.; Vera, J.; Pérez, A.; San-Blas, E.; Alvarado, Y. Theoretical Molecular Docking Study of the Structural Disruption of the Viral 3CL-Protease of COVID19 Induced by Binding of Capsaicin, Piperine and Curcumin Part 1: A Comparative Study with Chloroquine and Hydrochloroquine Two Antimalaric Drugs. 2020; https://doi.org/10.21203/rs.3.rs-21206/v1.

42. Kaisari, E.; Borruat, F.X. Keeping an Eye on Hydroxychloroquine Retinopathy. Klin Monbl Augenheilkd 2020, 237, 490-492, https://doi.org/10.1055/a-1098-8542.

43. Bhardwaj, S.; Tiwari, A. Highlights on Evidence-Based Treatment Strategies for COVID-19 : a Review. Letters in Applied NanoBioScience 2020, 3, 1359-1371, https://doi.org/10.33263/LIANBS93.13591371.

44. Hosny N.M.; Sherif, Y. Molecular Docking Study on Some Isonicotinoyl Hydrazide Derivatives as Potential Inhibitors of COVID-19. Letters in Applied NanoBioScience 2020, 3, 1217-1224, https://doi.org/10.33263/LIANBS93.12171224.

45. Saqib, S.; Zaman, W.; Ullah, F.; Majeed, I.; Ayaz, A.; Hussain Munis, M. F. Organometallic Assembling of Chitosan-Iron Oxide Nanoparticles with Their Antifungal Evaluation against Rhizopus Oryzae. Appl Organomet Chem 2019, 33, https://doi.org/10.1002/aoc.5190.

46. Vasantharaj, S.; Sathiyavimal, S.; Senthilkumar, P.; LewisOscar, F.; Pugazhendhi, A. Biosynthesis of Iron Oxide Nanoparticles Using Leaf Extract of Ruellia Tuberosa: Antimicrobial Properties and Their Applications in Photocatalytic Degradation. J Photochem Photobiol B Biol 2019, 192, 74-82, https://doi.org/10.1016/j.jphotobiol.2018.12.025.

47. Producing iron oxide nanoparticles for 150,000 COVID-19 tests per week https://www.nanowerk.com/nanotechnology-news2/newsid=54893.php (accessed Jun 12, 2020).

48. Sheridan, C. Fast, Portable Tests Come Online to Curb Coronavirus Pandemic. Nature biotechnology 2020, 515-518, https://doi.org/10.1038/d41587-020-00010-2. 